\title{
Analisis Schenkerian Pada Komposisi L'Armonia Opus 148.5 Gitar Klasik Karya Mauro Giuliani
}

\author{
Adityo Legowo ${ }^{1}$, Royke Bobby Koapaha ${ }^{2}$, dan Suryanto Wijaya ${ }^{3}$ \\ 1,3 Prodi Musik FSP ISI Yogyakarta \\ ${ }^{2}$ Prodi Penciptaan Musik FSP ISI Yogyakarta
}

\begin{abstract}
There are various types of music analysis, but what has been better known and studied in the writer's environment, is the analysis of musical forms. There are other ways in the field of analysis, one of which is Schenkerian analysis. Through this method of analysis we will get the deepest tonal structure of a tonal music system. This method is not yet common in Indonesia at this time. Therefore the writer wants to learn more about the schenkerian analysis. For discussion material will be limited to the work of Mauro Giuliani the composition of L 'Armonia opus 148. 5 for classical guitar. The consideration of the object of discussion is because the golden era of tonal music is the classical era. The work was made in classical times and was created by a mainstream composer for guitar instrument music. In addition, the work is played in a final project recital carried out by the author. So the hope of the writer with the analysis of the work of Mauro Giuliani can see the picture of other guitar composers in that era. Using qualitative descriptive methods with a musicological approach, especially music theory, it can be concluded that the form of the background of L'AAmonia's composition by Mauro Giuliani is a form of depth that is the result of reduction from previous forms. In this form there is an interruption that functions as an interrupter and is returned again to Kopfton 3 caused by a repeated structure. This form can be seen in the background discussion.
\end{abstract}

Keywords: schenkerian analysis; L'Oronia opus 148. 5.

\begin{abstract}
Abstrak
Ada beragam jenis cara analisis musik namun yang selama ini lebih dikenal dan dipelajari di lingkungan penulis, adalah analisis bentuk musik. Ada cara lain dalam bidang analisis, salah satunya adalah analisis schenkerian. Melalui cara analisis tersebut maka akan didapatkan struktur tonal yang terdalam dari sebuah sistem musik tonal. Cara ini sama sekali belum umum di Indonesia untuk saat ini. Maka dari itu penulis ingin mempelajari lebih dalam mengenahi cara analisis schenkerian. Untuk materi pembahasan akan dibatasi pada karya Mauro Giuliani komposisi L'Armonia opus 148.5 untuk gitar klasik. Adapun pertimbangan mengenahi objek pembahasan tersebut karena era keemasan musik tonal adalah jaman klasik. Karya tersebut dibuat pada waktu jaman klasik dan diciptakan oleh seorang komposer arus utama untuk musik instrumen gitar. Selain itu karya tersebut dimainkan dalam resital tugas akhir yang dilakukan oleh penulis. Sehingga harapan penulis dengan analisis karya Mauro Giuliani dapat melihat gambaran komponis gitar lainya pada era tersebut. Dgn menggunakan metode kualitatif desriptif dengan pendekatan musikologis, khususnya teori musik dapat disimpulkan bahwa bentuk background komposisi L'Armonia karya Mauro Giuliani adalah bentuk kedalaman yang merupakan hasil reduksi dari bentukbentuk sebelumnya. Di dalam bentuk ini terdapat interruption yang berfungsi sebagai penyela dan dikembalikan lagi ke kopfton 3 yang disebabkan oleh adanya struktur yang diulang. Bentuk tersebut dapat dilihat pada pembahasan background.
\end{abstract}

Kata kunci: analisis schenkerian; L'Armonia opus 148. 5

\section{Pengantar}

Karena sistem tonal dan analisis Shenkerian belum begitu banyak dibicarakan di lingkungan penulis, maka penulis ingin mengupas lebih dalam tentang sistem tonal melalui cara analisis Shenkerian dengan objek komposisi L'Armonia karya Mauro Giuliani. Dengan cara ini akan didapatkan sistem tonal yang lebih mendalam dan juga 
memperkenalkan sistem tersebut khususnya manfaat analisis sistem tonal.

Adapun pertimbangan mengenai objek penelitianya adalah komposisi L'Armonia karya Mauro Giuliani karena era keemasan musik tonal adalah jaman klasik. Karya tersebut dibuat pada waktu jaman klasik dan diciptakan oleh seorang komposer arus utama untuk musik instrumen gitar. Selain itu karya tersebut dimainkan dalam resital tugas akhir yang dilakukan oleh penulis. Sehingga harapan penulis dengan analisis karya Mauro Giuliani dapat melihat gambaran komponis gitar lainya pada era tersebut.

Melihat bahwa pemahaman musik tonal masih belum optimal dan perlu dioptimalkan serta analisis Schenkerian masih menjadi hal yang baru di sekitar lingkungan penulis. Menurut pendapat penulis analisis schenkerian dapat mengoptimalkan pemahaman tentang musik tonal oleh karena itu penulis ingin meneliti lebih lanjut tentang objek tersebut melalui analisis Schenkerian.

\section{Pembahasan}

Secara garis garis besar analisis ini akan dibagi menjadi tiga tahap yaitu foreground, middleground dan background. Foreground merupakan tahap awal, middleground tahap tengah dan background tahap akhir. Masing-masing tahap berhubungan satu sama lain. Tahap foreground merupakan hasil elaborasi dari tahap middleground. Sedangkan tahap middleground merupakan hasil elaborsi dari tahap background.

\section{A. Analisis Foreground}

Foreground adalah sebuah analisis permukaan yang berhubungan dengan kedalaman lapisan musik. Foreground merupakan tahap yang paling awal dari analisis Schenkerian dan seperti yang sudah dijelaskan pada bab sebelumnya bahwa pada tahap ini merupakan analisis harmoni dengan pertimbangan vertikal maupun horisontal. Harmoni merupakan dasar yang sangat penting dalam analisis ini. Dari tahap ini perjalanan analisis mulai dilakukan. Hasil analisis tahap foreground akan menentukan ke tahap selanjutnya (midleground dan background).

Pada tahap ini akan dibagi menjadi dua yaitu tahap satu foreground dan tahap dua foreground persiapan menuju middlegorund:

1. Tahap satu foreground

Pada tahap ini merupakan tahap yang paling awal dari proses analisis. Pada intinya tahap satu foreground ini adalah analisis hamoni secara vertikal maupun horizontal. Secara vertikal berhubungan dengan kualitas harmoni sedangkan secara horizontal berhubungan dengan progresi harmoni. Teknik penulisan yang dilakukan sebagai berikut :

a. Menandai progresi harmoni menggunakan angka romawi dan mencantumkan figur bas.

b. Kalau ada modulasi dapat ditandai sebagai akor yang disesuaikan dengan tonalitas tersebut. Selanjutnya dalam hal ini modulasi akan disebut sebagai tonicizations.

Berikut ini merupakan contoh beberapa potongan dari analisis foreground karya L'Armonia karya dari Mauro Giuliani Op. 148. 5.



Notasi 1. analisis foreground birama 1-9

Analisis foreground di atas bermain didalam tangga nada E mayor, disertai angka romawi di bawah staf notasi berfungsi sebagai tanda progresi, tanda kualitas akor 
dan sebagai figur pembalikan atau posisi dasar.

Ada beberapa kasus tonicizations yang ditemukan penulis dalam karya tersebut. Salah satu contoh kasus itu dapat dilihat pada keenam birama di bawah merupakan kasus tonizitation dari E mayor ke C mayor.
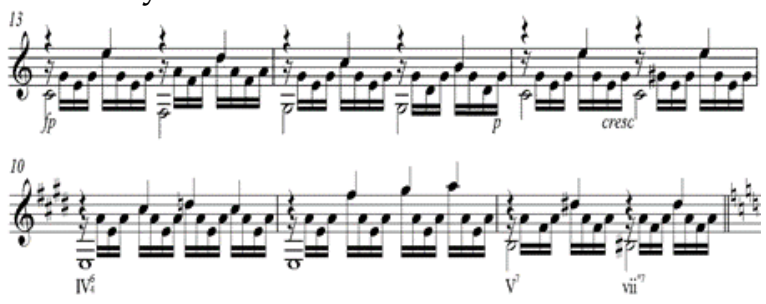

Notasi 2. Tonizization E mayor ke C mayor, dari birama 10-15

Selain kasus tonicizations ada kasuistik lain yang menarik dalam menandai progresi hamoni pada karya tersebut. Kasus itu terdapat pada birama 60 ketukan pertama. Nada G\#, D\#, F penulis memaknai sebagai akor vii/V karena merupakan akor bantu dari V. Namun hal tersebut masih menjadi sebuah ganjalan, karena nada ters dari G\# tidak muncul. Sedangkan peran nada ters pada struktur harmoni sangat penting. Kasus tersebut bisa dilihat di bawah ini :

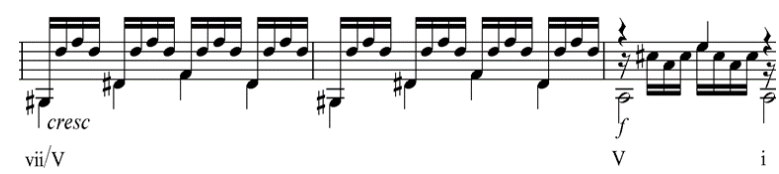

Notasi 3 akor vii/V tanpa ters dari birama 6061

Masih ada beberapa contoh tonizization yang terdapat dalam komposisi L'Armonia karya dari Mauro Giuliani Op. 148. 5 untuk lebih lanjutnya bisa dilihat pada lampiran.

Dari hasil analisa foreground di atas dapat disimpulkan bahwa, secara garis besar di dalam karya tersebut terdapat beberapa progresi tonalitas yang tertera pada tabel di bawah ini yaitu :

Tabel 1.tonalitas

\begin{tabular}{|c|c|c|c|c|c|c|c|c|}
\hline T & E & C & E & F & dm & D & c\#m & E \\
\hline$\underline{\text { L.B }}$ & 11 & 3 & 28 & 10 & 11 & 5 & 5 & 27 \\
\hline N.B & $1-12$ & $13-16$ & $17-45$ & $46-56$ & $57-68$ & $69-74$ & $75-80$ & $81-108$ \\
\hline
\end{tabular}

$\mathrm{T}=$ Tonality

J.B = Jumlahbirama

N.B=Nomorbirama
Masing - masing tonalitas tersebut berelasi satu sama lain. Adapun bagan relasi antar tonalitas terdapat di bawah ini:

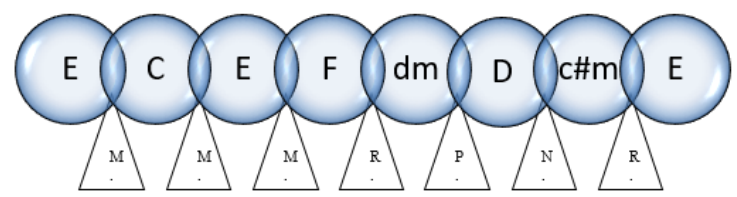

M. $=$ Mediant cromatic

R. = Relatif minor

P. = Paralel mayor

N. = Neapolitan

Pemaparan di atas, merupakan penjelasan tahap paling awal dari analisis schenkerian. Pada tahap selanjutnya masih dalam tahap foreground .

2. Tahap dua foreground (persiapan skor menuju Midleground dan menandai elaborasi dari foreground) :

Tahap ini masih dalam foreground, tetapi merupakan tahap persiapan menuju midleground. Hal ini memang sengaja dipisah dengan foreground sebelumnya dan dilakukan penulisan ulang pada notasi dengan cara menyederhanakan pola yang diulang-ulang. Hal tersebut dikarenakan untuk menghindari kekusutan dalam notasi. Sehingga dengan harapan melancarkan analisis ke tahap selanjutnya. Langkah langkah teknis yang dilakukan sebagai berikut:

a. Persiapan skor :

(1). Menghilangkan semua tangkai.

(2). Menghilangkan garis birama.

(3). Menghilangkan pengulangan nadanada dan phrases yang sama.

b. Elaborasi foreground :

Menandai elaborasi langsung dari harmoni foreground menggunakan slurs dan singkatan seperti dibawah ini :

- Arpeggiation (Arp.)

- Linear progressions (3-prg,4prg dan seterusnya)

- Neighbor notes (N)

c. Menulis kembali notasi dalam skala yang lebih besar tanpa merubah struktur melodi, 
iringan dan bas. Hal tersebut dikarenakan untuk menghindari kekusutan dalam notasi. d. Menandai elaborasi foreground lainya yang tidak ada didalam kategori diatas misalnya chomatic passing notes atau suspensions.

e. Elaborasi harmoni dalam skala yang lebih besar seperti contoh akord I-V-I dapat dimaknai sebagai hasil elaborasi dari akor I.

Berikut merupakan hasil analisis dari tahap ini:
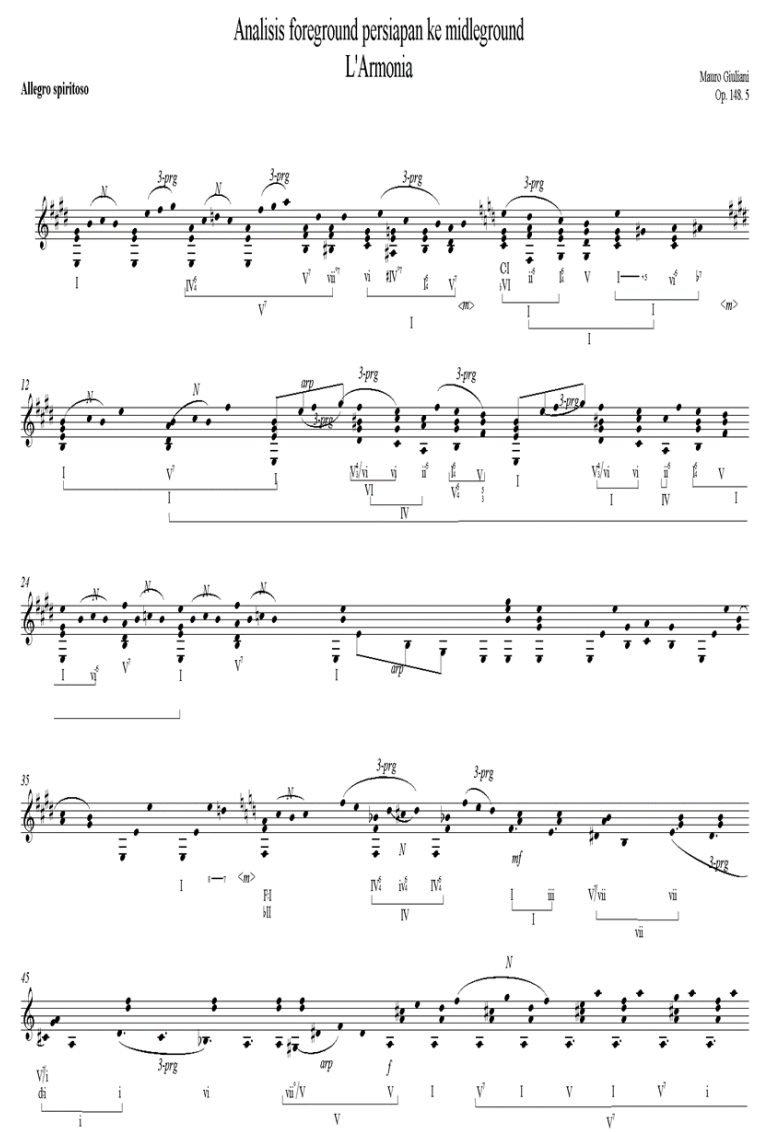

Notasi 4 analisis foreground persiapan ke middleground dari birama 1-108

Contoh di atas garis yang terdapat diantara angka romawi mempunyai arti bahwa akor yang terdapat di atas garis merupakan hasil elaborasi dari akor yang berada di bawah garis. Seperti contoh pada bagian awal terdapat: akor IV-V-vii merupakan hasil elaborasi dari akor V.



Notasi 5. Hasil elaborasi akor dari birama 3-5

\section{B. Analisis Middleground}

Middleground merupakan tahap elaborasi skala yang lebih besar dari tahap sebelumnya dengan kata lain tahap ini merupakan tahap tengah di antara tahap sebelumnya (foreground) dan tahap selanjutnya (background). Tahap ini merupakan hasil reduksi dari tahap sebelumnya. Penulis mulai mempertimbangkan ursatz pada tahap ini. Tidak ada tolak ukur yang pasti pada tahap middleground, artinya bahwa disisi lain dari analisis ini terdapat sisi objektifitas. Pada tahap ini penulis mulai menandai linear dalam skala yang lebih besar dan unit harmoni dengan beberapa pertimbangan :

1. Gerak alur melodi, dalam arti bahwa gerak melodi tersebut harus melangkah, sederhana dan halus.

2. Linear pattern yang bagus adalah ketika kondisi antara kontrapung dan harmoni didukung ( passing dan neighbor notes harus dibuat konsonan oleh garis bas ).

3. Keputusan mengambil nada- nada dalam stuktur harus mempertimbangkan antara melodi dan metrik yang menonjol (nadanada yang diambil harus berdasarkan pada keunggulan atau keistimewaan nada tersebut sesuai dengan posisi mereka didalam tekstur dan birama yang telah diperhitungkan).

Adapun mengenahi teknik penulisanya sebagai berikut :

1. Menggunakan tangkai nada untuk menunjukan elaborasi di dalam skala yang lebih besar dan menandai harmoni menggunakan angka romawi untuk dapat menjelaskan tentang elaborasi yang lebih lanjut.

2. Untuk menandai elaborasi dari middleground digunakan kombinasi tiang,bendera dan slurs sebagaimana sudah dijelaskan pada bab sebelumnya.

3. Menggunakan tiang bawah di dalam staf bas untuk menandai roots dengan prinsip harmoni yang mendukungnya.

4. Menandai unit harmoni menggunakan garis di bawah angka romawi sebagai tanda 
untuk elaborasi harmoni seperti contoh akor II atau IV bisa dianggap sebagai akor $\mathrm{V}$ dengan cara memberi garis dibawah kedua akor tersebut. Hal ini sangat membantu untuk menemukan akor dasar V-I atau V-V. 5. Menggunakan slurs untuk menghubungkan arpeggiation utama dalam garis bass.

6. Menggunakan dotted slurs bila dibutuhkan untuk menunjukan ketika dua unit linear foreground adalah elaborasi dari nada yang sama ( dua nada di dalam oktaf yang terpisah ).

7. Menggunakan tangkai nada dan garis diagonal untuk menjelaskan bagian - bagian seperti unfolding dan voice exchange, yang melibatkan pergerakan diantara dua nada yang berbeda. Berikut ini merupakan hasil analisis pada tahap middleground:

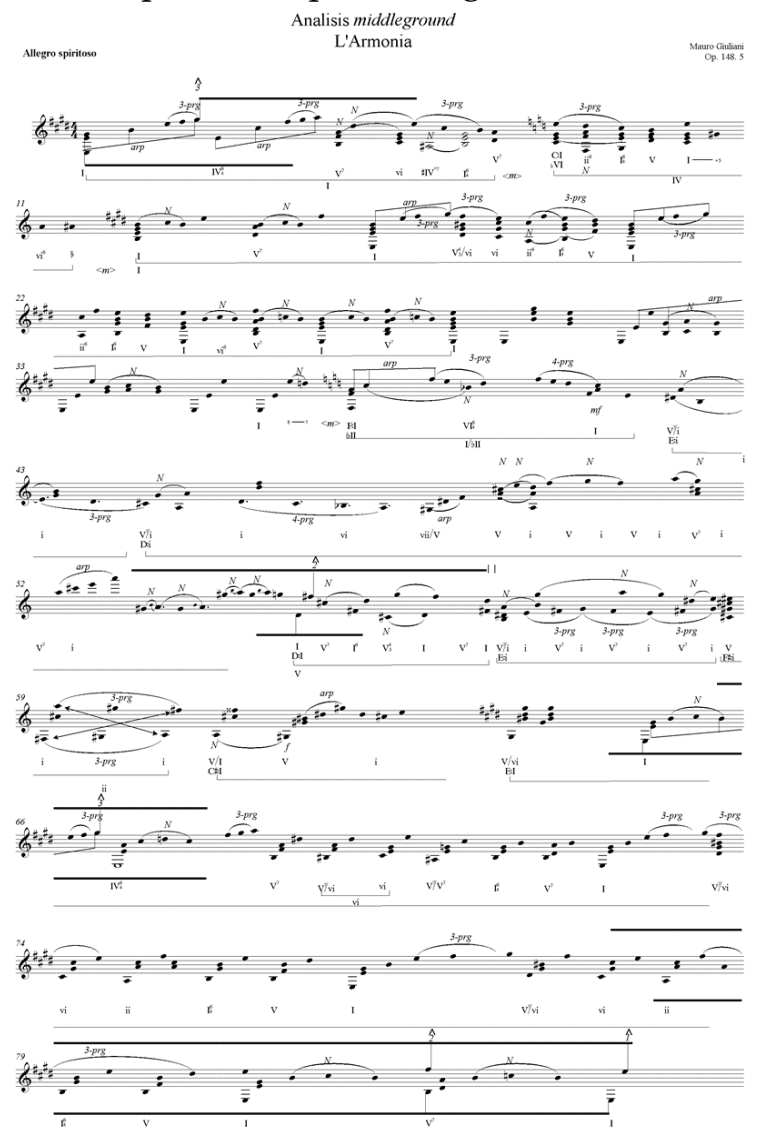

Notasi 6. Analisis middleground dari birama $1-108$

Dari hasil analisis Middleground di atas, penulis sudah menemukan bakal Ursatz.
Bakal Ursatz tersebut adalah . Adapun mengenahi pertimbangan dari hasil tersebut adalah :

1. Melalui analisis di atas penulis mentafsirkan bahwa dari birama satu sampai enam puluh delapan, merupakan hasil elaborasi dari akor I. Kopfton 3, jatuh pada nada mi / G\# yang terletak pada birama dua. Pertimbangan hal tersebut karena :

a. Terletak pada awal karya.

b. Dari ketiga jenis Ursatz, yang muncul adalah kopfton 3 .

c. Kopfton 3 jatuh pada akor I.

2. Pengambilan kopfton 2 jatuh pada nada re / $\mathrm{F}$ \# pada birama enampuluh sembilan dengan pertimbangan bahwa semua akor primer bisa dibantu tiga ke atas atau tiga ke bawah (subordinat chord). Seperti yang sudah dijelaskan pada bab sebelumnya bahwa dalam analisis ini salah satunya mencari struktur pokok progresi akor I-V-I. Nada re / F\# diperoleh dari akor D mayor. Akor ini dianggap akor $\mathrm{V}$ dari tangga nada $\mathrm{E}$ mayor karena hasil subordinat chord dari B. Nada F\# yang diambil pada awalnya bukan merupakan alur melodi, namun dalam hal tersebut bukan berarti tidak bisa mendapatkan alur urlinie seperti yang diharapkan. Penulis menggunakan subtitution sebagai pengganti nada F\# karena nada tersebut muncul pada ketukan selanjutnya dan merupakan bagian dari alur melodi. Sehingga dengan cara tersebut penulis bisa mendapatkan urlinie seperti yang diharapkan.

3. Kopfton 3 muncul lagi di birama delapan puluh empat dengan sruktur yang sama. Hal tersebut menimbulkan kecurigaan penulis bahwa jenis ursatz tersebut adalah interruptions.

4. Kopfton 2 muncul lagi pada birama sembilan puluh delapan akan tetapi, tidak sama persis seperti kopfton sebelumnya. Perbedaanya adalah pada kopfton ini struktur bassbrechung jatuh pas pada akor dominant. 
5. Kopfton 1 jatuh pada birama seratus dua, dengan pertimbangan bahwa struktur musik tersebut sudah selesai dan bergerak kembali ke nada do / E . Sedangkan birama selanjutnya hanya merupakan perpanjang dari birama seratus dua. Hal tersebut bisa dilihat pada birama sesudahnya hanya memainkan struktur akor yang sama yaitu hanya bermain pada wilayah akor E mayor.

\section{Analisis Background}

Merupakan tahap paling akhir dari analisis schenkerian. Dengan kata lain disini merupakan analisis struktur tonal yang paling mendasar dari karya tersebut. Nadanada yang ada dalam analisis background merupakan dihasil reduksi dari tahap sebelumnya. Teknis yang digunakan atau dipertimbangkan sebagai berikut :

1. Identifikasi urlinie dan bassbrechung dengan pertimbangan :

a. Urlinie harus bergerak turun dan melangkah menuju 1 dengan beberapa kemugkinan Kopftone : 3, 5 atau 8.

b. Setelah menetapkan urlinie didalam tingkat tangga nada, kopftone selanjutnya harus bergerak melangkah turun dan tidak dapat kembali ke tingkat sebelumnya. Berikut ini merupakan contoh dari ilustrasi kalimat tersebut. Urlinie yang teridentifikasi 5432 1, ketika pergerakan kopftone sampai pada 4 , gerakan selanjutnya harus berlanjut ke 321 dan tidak boleh kembali lagi ke 5 . Sebuah pengecualian pada kasus interruption ketika kopftone bergerak setelah 2 akan kembali lagi ke urlinie yang asli.

c. Untuk urlinie dari 5 atau 8, agar dapat meyakinkan harus benar - benar didukung dengan harmoni dan kontrapung.

2. Eksplorasi kemungkinan standar elaborasi ursatz pada level middleground (nada- nada urlinie dan bassbrechung dapat diperpanjang secara langsung) seperti initial ascent atau interruption.

Adapun teknik penulisan dari tahap ini sebagai berikut :
1. Urlinie ditandai dengan tangkai nada yang mengarah ke atas, dan masing- masing nada yang bergerak turun diberi tanda yang sesuai dengan tingkat tangga nada yang diwakili dengan hubungan kunci tersebut. Kopfton ditandai dengan caret $\left({ }^{\wedge}\right)$ dengan tujuan agar dapat dibedakan dengan nomor lain.

2. Bassbrechung (I-V-I) ditandai dengan tangkai turun dan nada- nada yang menjadi akar dari akor dihubungkan dengan garis horizontal.

3. Interuption ditandai dengan garis double slash setelah 2.

4. Elaborasi yang berbeda register dapat digunakan tanda panah dan dotted slurs.

5. Elaborasi perubahan suara dapat ditandai dengan tangkai dan panah yang sesuai.

Berikut ini merupakan hasil analisis background:

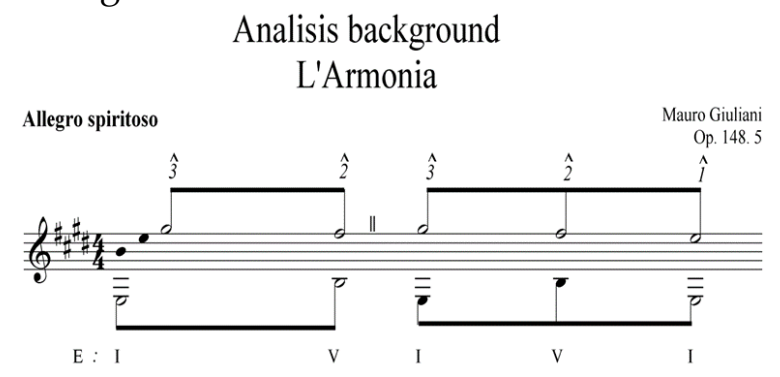

Notasi 8. Analisis background

Notasi di atas menunjukan hasil akhir analisis lagu L'Armonia karya Mauro Giuliani Op. 148. 5 didekati dengan initial ascent dengan kopfton 32 garis slash yang menunjukan inrterruptions kemudian dilanjutkan lagi dengan kopfton 321.

\section{Penutup}

Dari hasil pemaparan analisis di atas yang terdiri dari tiga tahap yaitu foreground, middleground dan background setiap tahap mempunyai kesan bunyi yang berbeda. Pada tahap foreground, merupakan tahap kasunyatan dari lagu tersebut. Tahap middleground, lagu tersebut menjadi bias karena sudah tidak terlacak hal itu disebabkan nilai ritmis hilang, sebagian frase yang sama hilang, tanda sukat hilang, garis 
birama hilang, nada yang sama hilang. Setelah kedua tahap tersebut, sampailah ke tahap terakhir yaitu background, merupakan tahap yang paling dalam dan mendasar karena pada tahap ini merupakan hasil reduksi secara besar-besaran dari tahap sebelumnya. Pada tahap background menunjukan karakteristik mendasar dari sistem tonal yaitu hirarki nada tonika dan dominan.

Dalam penelitian ini ternyata tidak semudah yang dibayangkan penulis. Ada beberapa kendala yang dihadapi oleh penulis ketika melakukan penelitian ini. Ada dua kendala yaitu kendala dalam analisis harmoni yang dapat menimbulkan berbagai tafsir dan kendala penulisan notasi (Dalam hal ini penulis menggunakan software Sibelius 5).

Oleh sebab itu dari kedua kendala diatas maka penulis menyarankan jika akan melakukan penelitian yang sama maka kuasailah dan pertimbangkan sematang mungkin dalam menentukan harmoni dan kuasailah software yang akan digunakan.

\section{Referensi}

Ammer, Christine. The Facts On File Dictionary of Music, Fourth Edition, (Facts On File Inc,United States of America, 2004).

Cope, David. Techniques of the Contemporary Composer (New York, Schirmer, Thomson Learning, 1997).

Kasir Ibrohim. M. Kamus Lengkap 29 Milryard. (Surabaya, Hikmah Jaya, 2006).

Keraf, Gorys. Komposisi. (NTT, Nusa Indah,2004).

Kotska, Stefan. Material and Techniques of Twentieth-Century Music.(Texas, University of Texas at Autin, 2006).
Nurden, Hugo. Fundamental Counterpoint, (Boston, Cressendo Publishing Company, 1969).

Pankhurs Tom. A Brief Handbook and Website for Schenkerian Analysis (United Kingdom, Liverpool Hope University, 2008).

Revised and Enlarged. Harvard Dictionary of Music, (United States of America, The Belknap Press of Harvard University Press Cambrige, 1974).

Suharsini Arikunto, Prof. Dr., Prosedur Penelitian-Suatu Pendekatan Praktek (Jakarta, Rineka Cipta, 2002) Tim Prima Pena. Kamus Ilmiah Populer. (Surabaya,Gitamedia Press, 2006). 